\title{
Transjugular Intrahepatic Portosystemic Shunt: A Bridge to Clinical Stability in Decompensated Cirrhosis
}

\author{
Daniela Reis ${ }^{a}$ Carlos Noronha Ferreira ${ }^{a, b}$ \\ a Serviço de Gastrenterologia e Hepatologia, Centro Hospitalar Universitário Lisboa Norte, EPE, Lisbon, Portugal; \\ ${ }^{b}$ Clínica Universitária de Gastrenterologia, Faculdade de Medicina da Universidade de Lisboa, Lisbon, Portugal
}

Keywords

Portal hypertension · Advanced cirrhosis - Transjugular intrahepatic portosystemic shunt

\section{Shunt portossistémico intra-hepático transjugular: uma ponte para a estabilidade clínica na cirrose descompensada}

\section{Palavras Chave}

Hipertensão portal · Cirrose avançada $\cdot$ Shunt portossistémico intra-hepático transjugular

In this issue of GE - Portuguese Journal of Gastroenterology, Santos et al. [1] report outcome data on TIPS placement in patients with advanced cirrhosis from Portugal's premier liver transplant and interventional radiology center.

TIPS placement has a crucial role in the management of acute variceal bleeding (AVB). In patients with high risk of treatment failure (i.e., Child-Pugh class $C$ disease or class $\mathrm{B}$ disease and active bleeding at endoscopy), TIPS should be considered within $72 \mathrm{~h}$ of admission (preemptive TIPS), as it reduces rates of failure to control bleeding and rebleeding $[2,3]$. Improvement in survival has also been demonstrated by previous studies [2, 4]. However, this benefit might be limited to Child-Pugh class $\mathrm{C}$ disease, as showed by a recent study [3], supporting the view that preemptive TIPS should be the treatment of choice in this sub-group of high risk patients. Regarding secondary prophylaxis, TIPS can be considered in patients who rebleed despite conventional therapy, and in selected patients with gastric varices, TIPS plus embolization can already be considered as first-line therapy [5].

Refractory ascites is another important indication for TIPS placement. Within 4 to 6 weeks of TIPS placement, portal pressure is reduced with increased cardia output resulting in increased natriuresis and fluid excretion [6, 7]. Although the effect of TIPS placement on survival in these patients is still controversial, Bureau et al. [8] showed that TIPS could improve 1-year transplant free survival when compared to large volume paracentesis with albumin infusion, suggesting that TIPS should be the therapeutic option to control recurrent ascites in selected patients [8].

TIPS has been recommended in selected cases of recurrent symptomatic hepatic hydrothorax and may improve renal function in some patients with hepatorenal
This article is licensed under the Creative Commons AttributionNonCommercial-NoDerivatives 4.0 International License (CC BYNC-ND) (http://www.karger.com/Services/OpenAccessLicense) Usage and distribution for commercial purposes as well as any distribution of modified material requires written permission. 
syndrome $[5,7]$. The prognostic role of neoadjuvant TIPS in patients undergoing elective extrahepatic surgery has also been reported $[9,10]$.

In this retrospective, single-center cohort, 78 TIPS were performed in the same department from January 2015 until November 2018. Technical success was achieved in $97.4 \%(n=76)$. Mean pre-TIPS portosystemic pressure gradient (PPG) was $18.1 \pm 5 \mathrm{~mm} \mathrm{Hg}$ and postTIPS PPG was $12 \pm 5 \mathrm{~mm} \mathrm{Hg}$, with a mean decrease of 6 $\pm 3 \mathrm{~mm} \mathrm{Hg}$.

It should be noted that post-TIPS PPG measured under general anesthesia does not accurately predict the risk of decompensation after TIPS placement [11]. Additionally, it has been suggested that the optimal timing to measure post-TIPS PPG should be at least $24 \mathrm{~h}$ after the procedure [12]. This avoids incorrect estimation of the PPG that will be maintained after TIPS placement [12].

Fifty-one patients were included in the final study sample, after exclusion of those with technical failure or loss of follow-up. Most were male $(75 \%, n=38)$ and had alcohol-related liver disease $(57 \%, n=29)$. Indications for TIPS were mainly refractory ascites $(65 \%, n=33)$ and therapeutic refractory or recurrent variceal bleeding $(35 \%, n=18)$.

After a mean follow-up of $15.7 \pm 15$ months, complete control of refractory ascites was achieved in 15/33 (45.5\%) patients. A total of $22 \%(4 / 18)$ developed recurrence of variceal bleeding which was associated with lower baseline hemoglobin values compared to those who did not $(p=0.03)$.

In this study, hepatic encephalopathy (HE) occurred in $41 \%$ of patients $(n=21)$ which was consistent with other reports $[3,13]$. In fact, HE has been described as a major adverse event of TIPS insertion [13]. Nevertheless, in patients with difficult to control ascites, no difference was found concerning the risk of HE between TIPS group when compared to conventional therapy group [8]. Stent reduction or TIPS occlusion may be required for managing post-TIPS HE if laxative treatment is not sufficient [5].

Regarding mortality, 6 (11.7\%) patients died within 1 month after the TIPS procedure. Significantly higher mortality was noted in patients with advanced cirrhosis (Child-Pugh score $>9$ points $[p=0.01]$ and MELD score $>19$ points $[p=0.02])$ and in those with prior HE $(p=$ $0.001)$. This last finding is interesting. Indeed, HE is clearly underestimated by MELD score and has been described as an independent risk factor for mortality in patients awaiting liver transplantation $[14,15]$.

It is noteworthy that, despite the evidence of a positive impact of TIPS on survival in variceal bleeding in patients with advanced cirrhosis (Child-Pugh C), it is still not commonly used as a first line therapeutic approach and often used as a salvage therapy [3]. It has been suggested that patients with advanced cirrhosis and variceal bleeding who may benefit from preemptive TIPS should be transferred to reference centers [3]. We should perhaps take advantage of the "fast-track" concept that already exists, for instance, in acute coronary syndrome or in stroke patients, and create a specific circuit for selected cirrhotic patients, especially for those who are candidates for liver transplantation.

In conclusion, though retrospective, this study emphasizes the value of TIPS placement in the management of portal hypertension-related complications in advanced cirrhosis. HE is a common adverse event after TIPS insertion but its incidence does not seem to be greater than in patients with difficult to control ascites managed by conventional medical strategy. An effort should be made to measure post-TIPS PPG after the patient awakens from anesthesia as this value correctly reflects long-term PPG.

\section{Conflict of Interest Statement}

The authors have no conflicts of interest to declare.

\section{Author Contributions}

Daniela Reis reviewed the literature and wrote the manuscript and Carlos Noronha Ferreira revised it for important intellectual content.

References

1 Santos S, Dantas E, Veloso Gomes F, Costa N, Hugo Luz J, Bilhim T, et al. Retrospective study of transjugular intrahepatic portosystemic shunt placement for cirrhotic portal hypertension. GE Port J Gastroenterol. 2020; https://doi.org/10.1159/000507894.

2 García-Pagán JC, Caca K, Bureau C, Laleman W, Appenrodt B, Luca A, et al.; Early TIPS (Transjugular Intrahepatic Portosystemic Shunt) Cooperative Study Group. Early use of TIPS in patients with cirrhosis and variceal bleeding. N Engl J Med. 2010 Jun;362(25): 2370-9.

3 Hernández-Gea V, Procopet B, Giráldez Á, Amitrano L, Villanueva C, Thabut D, et al.; International Variceal Bleeding Observational Study Group and Baveno Cooperation. Preemptive-TIPS Improves Outcome in HighRisk Variceal Bleeding: An Observational Study. Hepatology. 2019 Jan;69(1):282-93. 
4 Garcia-Pagán JC, Di Pascoli M, Caca K, Laleman W, Bureau C, Appenrodt B, et al. Use of early-TIPS for high-risk variceal bleeding: results of a post-RCT surveillance study. J Hepatol. 2013 Jan;58(1):45-50.

5 Tripathi D, Stanley AJ, Hayes PC, Travis S, Armstrong MJ, Tsochatzis EA, et al. Transjugular intrahepatic portosystemic stentshunt in the management of portal hypertension. Gut. 2020 Jul;69(7):1173-92.

6 Burgos AC, Thornburg B. Transjugular Intrahepatic Portosystemic Shunt Placement for Refractory Ascites: Review and Update of the Literature. Semin Intervent Radiol. 2018 Aug; 35(3):165-8.

7 Angeli P, Bernardi M, Villanueva C, Francoz C, Mookerjee RP, Trebicka J, et al.; European Association for the Study of the Liver. Electronic address: easloffice@easloffice.eu; European Association for the Study of the Liver. EASL Clinical Practice Guidelines for the management of patients with decompensated cirrhosis. J Hepatol. 2018 Aug;69(2):40660.

8 Bureau C, Thabut D, Oberti F, Dharancy S, Carbonell N, Bouvier A, et al. Transjugular
Intrahepatic Portosystemic Shunts With Covered Stents Increase Transplant-Free Survival of Patients With Cirrhosis and Recurrent Ascites. Gastroenterology. 2017 Jan;152(1):15763.

9 Fares N, Robic MA, Péron JM, Muscari F, Otal P, Suc B, et al. Transjugular intrahepatic portosystemic shunt placement before abdominal intervention in cirrhotic patients with portal hypertension: lessons from a pilot study. Eur J Gastroenterol Hepatol. 2018 Jan; 30(1):21-6.

10 Reverter E, Cirera I, Albillos A, DebernardiVenon W, Abraldes JG, Llop E, et al. The prognostic role of hepatic venous pressure gradient in cirrhotic patients undergoing elective extrahepatic surgery. J Hepatol. 2019 Nov;71(5):942-50.

11 Reverter E, Blasi A, Abraldes JG, MartínezPalli G, Seijo S, Turon F, et al. Impact of deep sedation on the accuracy of hepatic and portal venous pressure measurements in patients with cirrhosis. Liver Int. 2014 Jan;34(1):1625.

12 Silva-Junior G, Turon F, Baiges A, Cerda E, García-Criado Á, Blasi A, et al. Timing Affects
Measurement of Portal Pressure Gradient After Placement of Transjugular Intrahepatic Portosystemic Shunts in Patients With Portal Hypertension. Gastroenterology. 2017 May; 152(6):1358-65.

13 Riggio O, Angeloni S, Salvatori FM, De Santis A, Cerini F, Farcomeni A, et al. Incidence, natural history, and risk factors of hepatic encephalopathy after transjugular intrahepatic portosystemic shunt with polytetrafluoroethylene-covered stent grafts. Am J Gastroenterol. 2008 Nov; 103(11):2738-46.

14 Kerbert AJC, Reverter E, Verbruggen L, Tieleman M, Navasa M, Mertens BJA, et al. Impact of hepatic encephalopathy on liver transplant waiting list mortality in regions with different transplantation rates. Clin Transplant. 2018 Nov; 32(11): 0-1. https://doi.org/10.1111/ ctr.13412.

15 Lucidi C, Ginanni Corradini S, Abraldes JG, Merli M, Tandon P, Ferri F, et al. Hepatic encephalopathy expands the predictivity of model for end-stage liver disease in liver transplant setting: evidence by means of 2 independent cohorts. Liver Transpl. 2016 Oct; 22(10):1333-42. 